\title{
NIILISMO E MODERNIDADE EM NIETZSCHE
}

\author{
Jeovane Camargo 1 \\ Universidade Federal de São Carlos (UFSCar) \\ https://orcid.org/0000-0002-6960-6110 \\ E-mail: acasadeasterion@gmail.com
}

\section{RESUMO:}

Face às atuais compreensões da violência, que tendem a apresentá-la sempre negativamente, a genealogia de Nietzsche permite entender que a violência também possui um caráter positivo no percurso histórico do ocidente. Ela possibilitou a instauração da civilização, na medida em que modelou um determinado tipo humano. A eticidade do costume e o direito primitivo foram mecanismos de violência e crueldade que tornaram o homem responsável, previsível e obediente às normas. Por meio da renúncia à satisfação imediata dos instintos, internalizou-se a culpa e se instituiu o homem civilizado. Mas nesse mesmo percurso cresceu e dominou o niilismo.

PALAVRAS-CHAVE: Violência; Eticidade do costume; Culpa; Civilização.

\section{NIHILISM AND MODERNITY BY NIETZSCHE}

\begin{abstract}
:
In view of the current understandings of violence, which tend to present it always negatively, Nietzsche's genealogy allows us to understand that violence also has a positive character in the historical course of the West. It enabled the establishment of civilization, to the extent that it shaped a particular human type. The morality of morals and primitive law were mechanisms of violence and cruelty that made man responsible, predictable, and obedient to standards. By renouncing the immediate satisfaction of instincts, one has internalized the guilt and one has instituted the civilized man. But in this same course grew and dominated the nihilism.
\end{abstract}

KEYWORDS: Violence; Morality of morals; Guilt; Civilization.

\footnotetext{
${ }^{1}$ Doutor em Filosofia pela Universidade Federal de São Carlos (UFSCar), São Carlos - SP, Brasil.
}

CAMARGO, Jeovane. Niilismo e modernidade em Nietzsche. Griot : Revista de Filosofia, Amargosa - BA, v.18, n.2, p.61-71, dezembro, 2018. 
Na perspectiva do homem contemporâneo, a violência se apresenta como desvio, transgressão, infração, violação em relação à previsibilidade de certo padrão de comportamento cuja representatividade está aos cuidados das instituições que alicerçam a vida política, econômica e cultural da era moderna. A institucionalização desse modelo de comportamento está amparada em uma ideia de progresso da razão, segundo a qual a humanidade estaria a caminho de um desenvolvimento sempre maior de seu cérebro e de suas capacidades lógico-racionais, além de seu próprio corpo (alongamento dos dedos, aumento do tamanho dos olhos, etc.). Raciocínio que se ampara na perspectiva darwinista e na sobrevida que o Iluminismo ainda encontra nos meios científicos. Desse modo, ao longo de um enorme percurso histórico, a humanidade teria alcançado pouco a pouco um sempre maior controle sobre seus instintos e pulsões mais básicos, como a agressividade, a crueldade, a rapinagem, o assalto, a satisfação imediata do desejo, até que enfim as diversas formas de violência do mundo pré-histórico e do antigo foram confinadas entre as linhas fronteiriças da racionalidade, isto é, entre mecanismos institucionalizados de controle. Estranhamente, aos olhos de Nietzsche, tais mecanismos são representados pela busca da verdade, pelo cristianismo, pela ciência e pela democracia — as instituições e os valores mais caros ao homem moderno.

Por um lado, encontra-se aqui um sentido negativo das instituições modernas, em face do qual, deve-se perguntar: qual seria pois o problema visualizado por Nietzsche ao defrontar-se com tais formas de organização e de valoração modernas? Sob que aspecto confinar as pulsões violentas, agressivas, cruéis do homem não representaria um progresso para a humanidade? Em que sentido tais instituições, tais formas de valoração podem se apresentar, negativamente, como medidas de controle, confinamento e exclusão de instintos e pulsões que, em outros períodos históricos, foram pródigos na criação de valores, fundadores de civilizações portadoras de elevada vida cultural?

Por outro lado, teriam também a violência e a crueldade um sentido positivo? Fundados por formas primitivas do direito e pela eticidade do costume, cruéis dispositivos de controle foram responsáveis pela configuração das primeiras formações sociais, assim como das mais elevadas organizações que se seguiram. Eles possibilitaram, por exemplo, que grupos humanos abandonassem os modos de vida baseados no assalto e na rapinagem e constituíssem as primeiras organizações estabelecidas em torno dos direitos de credor e devedor.

Para se entender a dimensão dos problemas levantados por Nietzsche, é preciso acompanhar a maneira como ele retraça o percurso histórico do ocidente ${ }^{2}$. $O$ ponto de inflexão desse percurso está na figura de Sócrates. Situado no período da decadência da tragédia antiga, no século $\mathrm{V}$ a. C., Sócrates compartilhava com os espectadores do teatro da época o fato de não mais entender o sentido da tragédia. Assim, contrapondo-se ao aspecto obscuro da arte trágica, Sócrates sentencia: "Tudo deve ser consciente para ser bom" (NIETZSCHE, NT, p. 81). Essa sentença deve ser entendia como "só o que é compreensível é verdadeiro", ou "só a verdade é virtuosa". Ela torna-se o princípio elementar do pensamento socrático, torna-se virtude, devendo-se a partir de então dissolver tudo o que se mostra obscuro,

${ }^{2}$ Sobre a reinterpretação da história europeia, ver "Como o 'mundo verdadeiro' se tornou finalmente fábula", em: NIETZSCHE. Crepúsculo dos ídolos.

CAMARGO, Jeovane. Niilismo e modernidade em Nietzsche. Griot : Revista de Filosofia, Amargosa - BA, v.18, n.2, p.61-71, dezembro, 2018. 
enigmático, e buscar a verdade de forma incondicional. Outro ponto importante relaciona-se à psicologia de Sócrates. Por não pertencer à nobreza, Sócrates nutriria, segundo Nietzsche, grande ressentimento contra os aristocratas, o que o levou a criar um mecanismo de vingança, qual seja, a maiêutica (certa forma de dialética). Possuidor de uma inteligência lógica descomunal ${ }^{3}$, Sócrates dominava e ao mesmo tempo se vingava da casta aristocrática por meio de sua dialética, na qual era imbatível. Dessa forma, nasce no ocidente a busca da verdade a todo custo, a tentativa incansável de desencobrir uma suposta realidade encoberta pelas aparências. A arte trágica passa então a incorporar cada vez mais o diálogo e se torna sempre mais explicativa (contrapondo-se ao mito) até desembocar na nova comédia, forma primitiva da literatura moderna. ${ }^{4}$

O aparecimento de uma suposta verdade por trás das coisas é o golpe final sobre a arte trágica e sobre o mundo propriamente grego. O helenismo ou mundo alexandrino que surge na sequência é, segundo Nietzsche, apenas uma sombra do que foram o período ático e o mundo homérico. Nestes, não havia ainda aparecido a ideia de uma verdade contraposta à aparência, de algo mais verdadeiro que as histórias míticas. Após a busca da verdade acarretar a dissolução do mundo grego e de todo o mundo antigo, surge uma nova verdade por trás das coisas: o cristianismo.

Contudo, ainda que tendo dominado por vários séculos, o mundo cristão havia se fundado sobre a mesma lógica socrática, a da verdade a qualquer preço. De maneira que essa lógica, incrustada em sua visão de mundo e expressando-se nos estudos bíblicos, na patrística e principalmente na escolástica, leva o cristianismo a paulatinamente implodir a si mesmo. A busca renovada e insaciável da verdade acaba por superar os valores cristãos e abrir caminho para a ciência, posto que a condição dogmática daqueles valores é depreciada por uma racionalidade cada vez mais perspicaz. Isso aconteceu muitas vezes na história do ocidente, sempre que o sentido causal, a compreensão das relações necessárias separadas de todo acaso e sucessão eventual, suplantou as explicações baseadas em causalidades fantásticas. Nesse sentido, não foram os ateus ou os cientistas que mataram Deus ao negarem sua existência, mas a lógica da busca da verdade a qualquer custo, a qual exige do mundo ocidental que ele passe a sempre novas verdades.

$O$ que, pergunta-se com o máximo rigor, venceu verdadeiramente o Deus cristão? A resposta está em minha Gaia Ciência, § 357: “A própria moralidade cristã, o conceito de veracidade entendido de modo sempre mais rigoroso, a sutileza confessional da consciência cristã, traduzida e sublimada em consciência científica, em asseio intelectual a qualquer preço". (NIETZSCHE, GM, p. 138).

A era moderna celebra então seu distanciamento face à aristocracia escravista do passado, às crenças irracionais e supersticiosas, e ergue seu monumento de verdades úteis e necessárias para a vida. A visão mítica e o deus cristão são

\footnotetext{
3 Segundo Nietzsche, é só a partir da derrocada dos valores aristocráticos (dominação, assenhoreamento, hierarquia, bravura, exuberância) e do consequente domínio dos valores das castas e classes baixas (ressentimento, vingança, prudência, compaixão, bondade) que a inteligência passa a primeiro plano: ela se torna crucial para o mundo dos negócios, da paz e da salvação da alma.

${ }^{4}$ Sobre a interpretação da figura de Sócrates, ver "O problema de Sócrates", em Crepúsculo dos ídolos. E sobre a interpretação nietzschiana da tragédia, ver principalmente $O$ nascimento da tragédia.
}

CAMARGO, Jeovane. Niilismo e modernidade em Nietzsche. Griot : Revista de Filosofia, Amargosa - BA, v.18, n.2, p.61-71, dezembro, 2018. 
substituídos pelo átomo, pela matéria e pela energia, mas a lógica das transposições de valores continua a mesma: a busca incondicional da verdade. Nesse sentido, não estaria o mundo científico moderno condenado a ser superado pela mesma lógica que o instituiu?

Com o percurso descrito acima, observamos o niilismo em operação. Ora, mas que tem a ver a busca da verdade com a "vontade de nada" característica do niilismo? Nos fragmentos póstumos de Nietzsche, encontra-se a seguinte formulação: "O que significa niilismo? - que os valores mais altos se desvalorizam" (NIETZSCHE, FF, p. 35). Face à busca da verdade a todo custo, desvanecem os supremos valores do mundo antigo; em seguida, desmoronam os pilares do cristianismo, sua crença "na glória de uma razão divina" (NIETZSCHE, GM, p. 138). Mas o que a busca incondicional da verdade esconde é sua negação das condições gerais da vida. A falsidade, o erro, a ilusão, a cegueira, o delírio, o engano, a crueldade, a violência fazem parte de tais condições gerais, de maneira que não há justificativa para se acreditar em um valor incondicional e exclusivo da verdade. Isso quer dizer que, mesmo num cálculo utilitário, não há como justificar a atribuição de um valor absoluto à utilidade e à necessidade da verdade para a vida. Em consequência, a eleição da verdade como valor absoluto deve decorrer de outro âmbito que não o da estrita utilidade ou o da pesquisa científica rigorosa. Tal eleição decorre de uma valoração, portanto do âmbito moral. Dessa forma, a crença na verdade, ou na busca da verdade, não é a expressão de uma lei ou fato científico. Muito pelo contrário, ela é expressão de um âmbito que a pesquisa científica procura banir como algo subjetivo, não científico. A crença na verdade é apenas uma estimativa de valor, uma valoração moral. Para se firmar como condicionamento exclusivo da vida em geral, ela precisa desqualificar, tornar ilegítimo todo outro condicionamento. Ela se revela enfim como "um princípio hostil às condições da vida em geral" (GIACOIA, 1989, p. 99). É assim que a busca da verdade está integrada ao niilismo, posto que ambos são negadores da vida, isto é, de seus pressupostos mais fundamentais: a ilusão, o erro, a falsidade, o engano, etc. Eles são "vontade de nada" enquanto vontade de algo outro que vida, algo outro que ilusão, engano, desejo, isto é, eles são a vontade de um valor último, do sentido último da existência, o qual justificaria todas as formas de dor e sofrimento e possibilitaria até mesmo que as condições gerais da vida fossem alteradas.

Ora, desde que a crença na verdade se revelou como simples estimativa moral de valor, devemos não apenas perguntar por que busca da verdade, mas mais radicalmente por que moral, posto que as condições gerais da vida se mostram imorais (como ilusão, erro, engano, etc.). Se foi uma estimativa de valor que instituiu o percurso histórico ocidental enquanto niilismo e busca da verdade, então é imprescindível que se faça uma crítica do valor dos valores que determinou o ocidente.

Assim, impõe-se que se faça, segundo Nietzsche, uma genealogia dos valores ocidentais. Não se trata de elaborar a história dos sistemas éticos dos diferentes povos, mas de compreender as condições e as circunstâncias em que tais valores surgiram e se desenvolveram. Trata-se de tomar conhecimento da instância originária de onde provem a consciência moral, de investigar as condições de possibilidade iniciais das formas e valores da moralidade ocidental. Só assim será possível reconhecer a moral cristã-moderna, assentada em valores como não- 
egoísmo, compaixão, abnegação e impessoalidade, como o "perigo entre os perigos", na medida em que ela nos conduz a sempre mais pessimismo e niilismo, dos quais uma das causas é a renúncia à satisfação dos instintos.

[...] por fim, uma nova exigência se faz ouvir. Enunciemo-la, esta nova exigência: necessitamos de uma crítica dos valores morais, o próprio valor desses valores deverá ser colocado em questão — para isto é necessário um conhecimento das condições e circunstâncias nas quais nasceram, sob as quais se desenvolveram e se modificaram [...]. (NIETZSCHE, GM, p. 12).

A genealogia empreendida por Nietzsche se iniciara já em Humano, demasiado humano (1878), no qual ele se propunha a fazer "uma história da gênese do pensamento" (NIETZSCHE, HDH, p. 26), e se amplia até a Genealogia da moral (1887), livro em que ele se detém especificamente em mostrar a eticidade do costume e as formas elementares do direito como formadores e instauradores das formas superiores de moralidade. Em tal genealogia, Nietzsche descobre que, no processo formativo da humanidade, desde sua pré-história, a eticidade do costume e o direito primitivo se construíram por meio da subjugação da anarquia pulsional originariamente constitutiva do homem. A primeira cunhagem, portanto, do que viria a ser o tipo humano civilizado teria se iniciado em sua pré-história. Mas essa modelagem não se deu devido à utilidade, ou devido à adaptação do tipo humano às condições externas adversas, como supõem as perspectivas darwinista e social. $\mathrm{O}$ caráter da adaptação é secundário, reativo. As forças modeladoras do homem foram antes ativas, espontâneas, agressivas, assujeitadoras, o que mostra a afinidade do mundo natural com a vontade de poder ${ }^{5}$, conceito que, em Nietzsche, define o que seja vida. A vontade de poder é uma força plástica, criadora de formas, instauradora de hierarquias, de distâncias; ela é ativa. Face ao caos pulsional originário do homem, àquela satisfação imediata dos instintos, foi necessário instaurar regras, diferenças, medidas, funções, para se imprimir nele as primeiras formas de organização social. Esse trabalho de modelagem da massa-homem foi levado a cabo por meio da eticidade do costume e do direito primitivo, os quais instituíram mecanismos de disciplina e coerção.

Um exemplo de tal trabalho de moldagem é o "Estado". Este se originou das hordas de homens sem consciência de culpa, sem responsabilidade, autênticos animais de rapina que submeteram populações numericamente maiores, inculcandolhes determinada organização, isto é, sua vontade. Nas palavras de Nietzsche: "o mais antigo 'Estado' [...] apareceu como uma terrível tirania, uma maquinaria esmagadora e implacável" (NIETZSCHE, GM, p. 69). Só mais tarde é que surgem organizações sociais com relações de sentido interno renovadas e melhor integradas.

Do mesmo modo, o aparecimento do indivíduo soberano, responsável, livre, capaz de determinar sua própria vontade, só foi possível pela sujeição das pulsões mais selvagens, pela aplicação de dispositivos de coerção e tortura. $O$ processo civilizatório, nesse sentido, é um espaço de domesticação e amestramento do animalhomem, um "prodígio de crueldade" do homem contra si mesmo.

As formas primitivas do direito e a eticidade do costume permitem, assim, uma modelagem do homem tanto em nível macro ("Estados" primitivos, diferenças

\footnotetext{
${ }^{5}$ Sobre o conceito de vontade de poder, ver: NIETZSCHE. Crepúsculo dos ídolos. E: FOGEL, G. Conhecer é criar.
}

CAMARGO, Jeovane. Niilismo e modernidade em Nietzsche. Griot : Revista de Filosofia, Amargosa - BA, v.18, n.2, p.61-71, dezembro, 2018. 
sociais de hierarquia e de poder) como em nível micro (psique individual hierarquizada de modo a haver harmonia entre as diferentes pulsões). A distância entre as castas sociais, sua hierarquização (o "pathos da distância") possibilitou a "espiritualização" da humanidade (aparecimento de distâncias, especificações de funções dentro da psique humana).

Sem o pathos de distância, tal como surge da inveterada diferença dos estamentos, do permanente olhar à distância dirigido pela classe dominante para além e para baixo sobre súditos e instrumentos e de seu permanente exercício de obedecer e comandar, manter os outros subjugados e distanciados, não poderia surgir tampouco, de modo algum, aquele outro pathos misterioso, aquele desejo de ampliar incessantemente as distâncias dento da própria alma. (NIETZSCHE, ABM, p. 153).

Desse modo, a origem do "bom" e do "ruim" não decorre da utilidade ou das vantagens concedidas àquele a quem o ato era praticado; antes, ela se origina na diferenciação entre nobres e servos, isto é, no distanciamento social e espiritual entre os estamentos, o que foi obra de dispositivos violentos de coerção. Assim é que começa a se modelar a consciência de responsabilidade, mais tarde denominada liberdade e razão.

Originariamente, o homem não é ético. Sua eticidade, seus costumes regrados e tradições precisaram ser impressos nele durante longo período de tempo, até que eles se tornaram hábito e se esqueceu dessa terrível origem. O recuo de Nietzsche às condições de possibilidade iniciais da consciência moral descobre que o dever moral não está alicerçado na própria razão humana, isto é, no sujeito de direito, tal como supõem as modernas teorias do direito ${ }^{6}$. Ao contrário, a consciência do dever moral foi construída a partir das formas primitivas do direito e da eticidade do costume.

A forma mais primitiva e elementar do direito é a obligatio contratual entre credor e devedor ${ }^{7}$. No contexto de compra e venda, o dever ou a obrigação significam "a representação do ato que se deve praticar ou de que se deve abster" (GIACOIA, 1989, p. 107). A lógica dessa relação pressupõe indivíduos capazes de cumprir a palavra empenhada, de garantir determinado comportamento no futuro, de responsabilizar-se pelo próprio comportamento ou ainda de prometer. Tal autonomia sobre a própria vontade não é uma qualidade inata do homem. Originariamente, sua consciência estava presa ao instante e tendia continuamente ao esquecimento ${ }^{8}$. Em face disso, para instaurar o sentimento de responsabilidade, foi necessário um longo, cruel e laborioso processo de modelagem, graças ao qual se estabeleceu finalmente um comportamento regular, previsível, calculável, regido por normas. O que se criou, enfim, foi uma memória, uma verdadeira memória da vontade. Segundo Nietzsche (GM, p. 46), contra a imediatez das pulsões e a ativa força de esquecimento, foram precisos instrumentos de mnemotécnica — a dor e o sofrimento - em um demorado exercício de crueldade. Por meio da punição, o credor participa de um privilégio de senhores, e experimenta o prazer de desprezar e maltratar alguém como inferior. A

\footnotetext{
${ }^{6}$ Sobre isso, ver: MIAILLE, M. Introdução crítica ao direito.

${ }^{7}$ Sobre isso, ver NIETZSCHE, GM, p. 49. A palavra alemã Schuld e a grega 'aııı significam tanto dívida como culpa, integrando assim o originário sentido econômico ao moral (NIETZSCHE, GM, p. 55).

${ }^{8}$ Uma das forças ativas, digestivas a integrar a fisiologia humana (Cf., GM, p. 46).
}

CAMARGO, Jeovane. Niilismo e modernidade em Nietzsche. Griot : Revista de Filosofia, Amargosa - BA, v.18, n.2, p.61-71, dezembro, 2018. 
punição, compensação por um dolo, consiste assim em um "convite e direito à crueldade" (NIETZSCHE, GM, p. 50).

A fim de criar no homem a consciência de uma obrigação, o responsabilizarse, foi preciso instaurar a memória da palavra empenhada e o respeito pela autoridade. Assim, a eticidade do costume se clarifica como "a obediência a costumes, não importa quais sejam": a obediência à tradição, à regra, ao indiscutível - ainda que os costumes não sejam mais do que "a maneira tradicional de agir e avaliar" longamente sedimentada na comunidade (NIETZSCHE, A, p. 17).

O sujeito de direito, as prerrogativas de direito e a justiça surgem desse processo. Nas obrigações implicadas na compra e venda aparecem indivíduos que se defrontam e se medem em torno de obrigações e deveres contraídos socialmente. Dessa forma, o direito concerne a "graus de poder reconhecidos e assegurados" (NIETZSCHE, A, p. 77) pelos indivíduos ou grupo social. Isso quer dizer que direitos e deveres, enquanto se originam das primitivas relações entre credor e devedor, são domínios de poder cuja manutenção exige o reconhecimento do grupo. Das relações entre credor e devedor, desse equilíbrio de forças, deriva ainda a noção mais geral de justiça ${ }^{9}$, cujo princípio elementar é o de que o descumprimento de uma obrigação implica em atentado a uma esfera de poder — a lesão de um direito deve ser reparada por um equivalente do ato danoso; o sentimento de poder ferido deve ser compensado por uma satisfação reparatória.

Em tempos primitivos, tal reparação era desempenhada pela crueldade, a qual era uma forma de satisfação face ao dano sofrido. Causar dor e sofrimento era uma compensação que visava recobrar no credor seu sentimento de bem estar, seu sentimento de poder. Dessa forma:

\begin{abstract}
A equivalência está em substituir uma vantagem diretamente relacionada ao dano (uma compensação em dinheiro, terra, bens de algum tipo) por uma espécie de satisfação íntima, concedida ao credor como reparação e recompensa [...]. (NIETZSCHE, GM, p. 49).
\end{abstract}

A pergunta que devemos fazer então é a seguinte: por que a reparação de um direito lesado encontra na crueldade sua expressão compensatória ${ }^{10}$ Nas origens das formações coletivas humanas, descobrimos a renúncia à satisfação instintiva, a qual fora lentamente forjada pela coerção do "Estado" e pelas obrigações contratuais de compra e venda. Contudo, a satisfação instintiva, o prazer na realização imediata das pulsões, o prazer na hostilidade, na agressividade, na crueldade, não desapareceram da fisiologia humana. A diferença instaurada é que agora eles encontram uma satisfação substitutiva nas representações do direito e da eticidade do costume. Ao longo de seu percurso, o mundo ocidental assistiu a transposições e reinterpretações da renúncia à satisfação instintiva, isto é, a diferentes formulações do direito e da eticidade do costume.

\footnotetext{
9 Sobre isso, ver também: JAEGER. "O estado jurídico e o seu ideal de cidadão". In: Paideia.

${ }^{10} \mathrm{Ou}$, nas palavras de Nietzsche: "em que medida pode o sofrimento ser compensação para a "dívida'?”. E ele logo responde: "Na medida em que fazer sofrer era altamente gratificante, na medida em que o prejudicado trocava o dano, e o desprazer pelo dano, por um extraordinário contraprazer: fazer sofrer..." (NIETZSCHE, GM, p. 50).
} 
Um exemplo de crueldade integrada ao direito apresenta-se na figura do homem que é expulso de uma comunidade primitiva. No seio dos bandos que exerciam a rapinagem, aquele que cometia uma infração, face às regras/ao direito do grupo, era excluído. Contudo, essa exclusão não significava banimento para outro lugar ou outra comunidade. Ao contrário, o infrator excluído ficava à mercê de atos de selvageria, de violência e de crueldade. Ele se tornava um excluído/incluído, posto que poderia ser agredido, violado ou assassinado sem motivos pelos membros da comunidade. Mais tarde, no direito romano, a figura do infrator recebe a denominação de homo sacer, embora sua condição de excluído/incluído não tenha se alterado. Justamente aí se funda também o direito moderno (Cf.: Giacoia, 2014, ps. $50-51)$.

Desse modo, pode-se entender que o amestramento do animal-homem, a civilização, é a "espiritualização" sempre crescente da crueldade. Novas satisfações, subterrâneas, surgem quando a satisfação dos instintos não encontra vazão externamente; ela então se volta para dentro, para a satisfação íntima. Nesse sentido, articulando renúncia à satisfação instintiva e "espiritualização", conclui Nietzsche:

[...] os velhos instintos não cessaram repentinamente de fazer suas exigências! Mas era difícil, raramente possível, lhes dar satisfação: no essencial tiveram de buscar gratificações novas e, digamos, subterrâneas. Todos os instintos que não se descarregam para fora se voltam para dentro — isto é o que chamo de interiorização do homem: é assim que no homem cresce o que depois se denomina sua "alma". (NIETZSCHE, GM, p. 67).

No primeiro livro publicado por Nietzsche, O nascimento da tragédia (1872), dois impulsos estão em rivalidade constante, o apolíneo e o dionisíaco. Este diz respeito a todas as pulsões naturais, selvagens, dissolventes, e aquele às pulsões organizadoras, limitadoras, regulamentadoras. A arte trágica seria o âmbito em que a força de dissolução dionisíaca encontra um limite, uma medida, na forma artística apolínea. De maneira que elas perpetuam seu combate, sem negarem a existência uma da outra, como dois inimigos que se respeitam e até se estimam. De forma semelhante, Nietzsche entende que uma organização sociocultural sadia não pode simplesmente sufocar as pulsões básicas do homem, pois assim elas se voltam para dentro, adoentando-o. Por isso ele critica o mundo democrático moderno, no qual a longa cunhagem de séculos forjou um tipo humano apenas reativo, previsível, enfim, o tipo que internalizou a culpa, tornando-se cansado, insatisfeito e pessimista - o tipo negador da vida.

No percurso histórico no qual o homem procura tornar-se "anjo", isto é, ético, "bom", cristão, democrático, moderno, corre ele também o perigo dos perigos: o momento aterrador em que o homem sente-se enojado do homem, o momento de asco ao homem. O homem, ao ter nojo de si mesmo, torna-se doente: o homem pois se torna doente do homem. Como isso acontece? Ora, a "caminho de tornar-se "anjo", foi preciso que o "bicho homem" aprendesse a se envergonhar de seus instintos", ou seja, que ele considerasse "repulsivas a alegria e a inocência do animal, e sem sabor a própria vida" (NIETZSCHE, GM, p. 52). Momento em que não apenas sua experiência particular torna-se sem sabor, mas também e principalmente a totalidade do existir. Está assim aberta a porta para o niilismo; o homem nega a vida

CAMARGO, Jeovane. Niilismo e modernidade em Nietzsche. Griot : Revista de Filosofia, Amargosa - BA, v.18, n.2, p.61-71, dezembro, 2018. 
terrena, carnal, mortal, plena de sofrimentos e que não fornece um sentido para o sofrer. A totalidade sócio-cultural se tornou de fato incapaz de oferecer qualquer valor mais alto que o da simples volição subjetiva individual, a qual, como não pode buscar limite senão em si mesma, é vazia de limite, vazia de sentido. Assim, o homem sofre do sentido, isto é, sofre de si mesmo, posto que está entregue ao ilimitado do seu desejo (volição subjetiva). Como seu desejo não pode encontrar limite em si mesmo, ele é vazio, infinito, ilimitado. Essa é a má consciência que acompanha toda volição subjetiva, a hybris constitutiva da índole moderna. Nenhuma satisfação particular preenche o desejo de satisfação; e o homem se vê condenado a procurar sempre mais adiante... mesmo que a satisfação vindoura não seja capaz de preencher seu desejo. A volição subjetiva individual é assim uma procura cega: sem saber o que procura, continua procurando. Quanto dissabor em tal volição, quanta má consciência! O homem está pois com nojo do homem.

A recusa às pulsões, aos instintos, a inibição à toda vontade de vida ${ }^{11}$, ou seja, a moral cristã-moderna, o estado de direito moderno, enquanto são eles "meio contra toda luta" e entendem que "toda vontade deve considerar toda outra vontade como igual", revelam-se pois um "princípio hostil à vida, uma ordem destruidora e desagregadora do homem (...), um sinal de cansaço, um caminho sinuoso para o nada" (NIETZSCHE, GM, p. 60).

Ao compor a Genealogia da moral, Nietzsche não está preocupado apenas em percorrer a história do ocidente, desencobrindo os pressupostos mais básicos das valorações morais, para assim fundamentar sua crítica aos valores cristãos e modernos; antes, seu interesse é mostrar como vida, isto é, vontade de poder, foi soterrada e encoberta paulatinamente pela eticidade do costume e inovações morais. A moralidade cristã principalmente e de modo propriamente danoso foi que operou a maior inversão de valores, levando o mundo antigo à derrocada, e fazendo com que a renúncia à satisfação dos instintos se tornasse uma luta interior do homem contra si mesmo. Mas na medida em que o homem deixou de temer os deuses e passou a entender sua própria natureza como má, perdeu ele também toda admiração por si mesmo. A vida assim tornou-se sem sabor.

Por outro lado, por mais que o homem procure negar a imediatez de suas pulsões, por mais que ele tenha se tornado modesto, bondoso e democrático, ele não deixa de corresponder à vida que ele mesmo é, ou seja, ele não deixa de ser vontade de poder. Dessa maneira, ao aprender a nada querer autenticamente, senão que a apenas consumir, escolher (entendendo mesmo que nisto consistiria a sua liberdade), o homem aprendeu a querer o nada, isto é, o ilimitado do seu desejo, o infinito de sua volição subjetiva. Apesar de toda inibição às suas pulsões, apesar do desaparecimento dos deuses antigos e, em seguida, do próprio deus cristão, o homem não pode deixar de querer, posto que desejar é constitutivo de sua fisiologia. Contudo, à ausência de limites e de sentido, ele se perde em si mesmo, e passa a querer o nada. Assim, "o homem preferirá ainda querer o nada a nada querer..." (NIETZSCHE, GM, p. 140). Ainda que caia no ilimitado da volição subjetiva, e que negue a vida em prol de outro mundo, o homem não deixa de ser vontade de poder. E é esta a condição fundamental encoberta pela sedimentação histórica, pela

11 Vida: "essencialmente, isto é, em suas funções básicas, a vida atua ofendendo, violentando, explorando, destruindo, não podendo sequer ser concebida sem esse caráter.” (NIETZSCHE, GM, p. 60).

CAMARGO, Jeovane. Niilismo e modernidade em Nietzsche. Griot : Revista de Filosofia, Amargosa - BA, v.18, n.2, p.61-71, dezembro, 2018. 
inversão de valores trazida pelo cristianismo ou pelo ocasional cansaço fisiológico do homem ocidental.

Violência e crueldade são, portanto, dimensões da vontade de poder e, como tais, impossíveis de serem separadas do homem. Nesse sentido é que o homem ingênuo da antiguidade, ao se dar momentos de crueldade e violência, como na guerra, na arte trágica ou no sacrifício, foi capaz de conciliar Dionísio e Apolo. Sua ingenuidade era a da satisfação dos instintos, sem consciência de culpa.

A derrocada dos deuses antigos, o ultrapassamento da ordem cósmica que selava o destino do homem e da comunidade foi possível na medida em que não apenas houve a inversão da primazia dos valores nobres para os das classes baixas, mas também porque o novo deus não exigia mais sacrifícios para apaziguar seu gosto pela crueldade; de modo imprevisto, o novo deus sacrifica a si mesmo pela redenção do homem, ou pelo perdão dos seus sacrilégios (pecados). $O$ homem não se vê mais à mercê das pulsões dos deuses, mas reconciliado com a vontade (ou razão) de um deus único. Contudo, a ruína da crença no deus cristão e a ascensão do mundo democrático moderno não decorrem da aparição de um novo deus nem levam à criação de um novo deus, senão que se caracterizam pela liberação desenfreada do desejo individual (volição subjetiva). Tal volição individual já estava presente na antiguidade e no desenrolar do cristianismo, mas ela era combatida pelo mito e pela fé - pela eticidade do costume. A destruição do mundo mítico e o definhamento da fé no Cristo deixam o homem entregue ao desejo individual sem freios. Isto quer dizer que o deus que restou é o nada, posto que a volição subjetiva não pode encontrar satisfação, procurando sempre novas e renovadas formas de querer: consumismo, cultura de massa, entorpecimentos, distrações.

O que poderia então fornecer o limite, o comedimento aos impulsos desnorteados da volição subjetiva? Essa é a questão para a qual o pensamento hoje deve se voltar. Face ao abismo do nada (o desejo desenfreado), o que resta de ascetismo cristão - certa disciplina moral não ainda de todo liquidada que poderia se oferecer como resistência à sanha individual? Ou ainda o ateísmo que medra vagarosamente nas mentes mais despertas, e que se expressa no objetivismo, no propósito de ter somente a realidade como critério de verdade - assim mostrando potencial de ultrapassamento da mística constitutiva de ideias como subjetividade, razão humana, sujeito de direito, liberdade, igualitarismo, etc? As leis instituídas não são suficientes, posto que, na medida em que desagradam a vontade individual, esta tende a continuamente desafiá-las. A modernidade não apresenta ainda uma resposta a tais questões. $\mathrm{O}$ homem atual é pois um limiar, uma ponte para o "além do homem", isto é, para além do moderno, para além da subjetividade, da liberdade sem freios. Enfim, como limiar, sentimos o perigo dos perigos: o nada ou... 


\section{Referências}

NIETZSCHE, F. O nascimento da tragédia. São Paulo: Cia. das Letras, 2008. (NT) . Humano, demasiado humano. São Paulo: Cia. das Letras, 2008. (HDH) - Aurora. São Paulo: Cia. das Letras, 2016. (A) - A gaia ciência. São Paulo: Cia. das Letras, 2012. (GC) . Assim falou Zaratustra. Petrópolis: Vozes, 2011. (AFZ) . Além do bem e do mal. São Paulo: Cia. das Letras, 2014. (ABM) . Genealogia da moral. São Paulo: Cia. das Letras, 2010. (GM) . Crepúsculo dos ídolos. São Paulo: Cia. das Letras, 2006. (CI) . Ecce Homo. São Paulo: Cia. das Letras, 2009. (EH)

. Fragmentos Finais. Brasília: Editora UnB, 2002. (FF)

GIACOIA JUNIOR, O. “O grande experimento: sobre a oposição entre eticidade e autonomia em Nietzsche". São Paulo: Revista Trans/form/ação, v. 12, 1989.

- "Estado, democracia e sujeito de direito: para uma crítica da política contemporânea". Brasília: Revista de Filosofia Moderna e Contemporânea, vol. 2, 2014 .

. "Violência e Racionalidade Jurídica. A Potência dos Meios". Revista Brasileira de Estudos Políticos, v. 108, 2014.

MIAILLE, M. Introdução crítica ao direito. Lisboa: Editorial Estampa, 2005. FOGEL, G. Conhecer é criar. São Paulo: Discurso Editorial e Ed. Unijuí, 2003. JAEGER, W. Paideia. São Paulo: Martins Fontes, 2013.

PASCHOAL, A. E. "O procedimento genealógico de Nietzsche". Revista Diálogo Educacional (PUCPR), v. 1, 2000.

. "Doença, saúde e grande saúde na filosofia de F. Nietzsche". In: Psicanálise em perspectiva III. Curitiba: Editora CRV, v. 1, 2012.

Autor(a) para correspondência: Jeovane Camargo, Universidade Federal de São Carlos, Departamento de Filosofia e Metodologia das Ciências, Rod. Washington Luiz, CEP 13565-905, São Carlos - SP, Brasil. acasadeasterion@gmail.com 